\title{
Comparison of The Effectiveness of Acceptance and Commitment Therapy (ACT) and Process Emotion Regulation Training in Quality of Life among Hemodialysis Patients
}

\begin{abstract}
Introduction: Kidney disease causes many physical and mental problems for the patient and reduces the quality of life of these people. The aim of the present study was to compare the effectiveness of acceptance and commitment therapy and process emotion regulation training in quality of life of hemodialysis patients.

Method: The statistical population of this semi-experimental study with Pretest-Posttest follow up design were all hemodialysis patients who referred to Loghman Hospital in Tehran in 2019. Among them the patients who were willing and qualified to participate in the study were selected in convenience and then randomly assigned to experimental and control groups (15 persons in the first experimental group, 15 persons in the second experimental group and 15 persons in waiting list control group). The research instrument was the quality of life questionnaire of Hayes et al. (2003). Research data were analyzed using mixed analysis of variance test.

Results: The results of data analysis showed that treatment based on acceptance and commitment and process emotion regulation training in the participants of the experimental groups compared to the control group had a significant effect on improving the quality of life of hemodialysis patients $(\mathrm{P}<0.05)$. Also, the effectiveness of acceptance and commitment therapy was higher on patients' quality of life $(\mathrm{P}<0.05)$.

Conclusion: Acceptance and commitment therapy and process emotion regulation training is effective on improving the quality of life of hemodialysis patients by increasing behavior control and the desire to experience a range of emotions.
\end{abstract}

Keywords: Acceptance and Commitment Therapy, Process Emotion Regulation Training, Quality of Life, Hemodialysis Patients

\footnotetext{
Affiliations

1- PhD student in Health Psychology, Kish International Branch, Islamic Azad University, Kish Island, Iran

2- Associate Professor, Department of Psychology, Kharazmi University, Tehran, Iran

Corresponding Author: Hatami513@gmail.com

3- Assistant professor, Department of Psychology, Karaj Branch, Islamic Azad University, Karaj, Iran

4- Associate Professor of Nephrology, Tehran University of Medical Sciences, Tehran Iran

5- Assistant professor, Department of Clinical Psychology, Roodehen

Branch, Islamic Azad University, Roodehen, Iran
}

Article Info

Authors:

Kalbasi $\mathrm{R}^{1 \odot}$

Hatami $\mathrm{M}^{2 *} \odot$

Sirafi MR ${ }^{3}$ ○

Hakemi MA ${ }^{4}$ e

Sabet $\mathrm{M}^{5} \odot$

Received: 2020/4/2

Accepted: 2020/8/5

E-Published: 2021/3/2

\section{Citation Subjects:}

ACT, Emotions, Self-Regulation, Health Related Quality of Life, Extracorporeal Dialysis 
فصلنامه يرستار و پزشك در رزم / تابستان 99 / سال هشتم

ISSN: 2645-3940 $\quad$ DOI:10.29252/npwjm.8.27.7

\section{مقايسه درمان مبتنى بر يذيرش و تعهد و نظمجويى فر آيندى هيجان در كيفيت زندكى بيماران همودياليز}

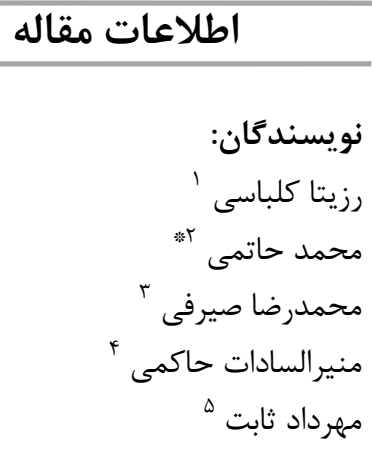

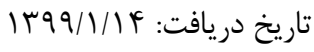

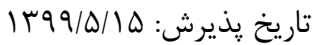

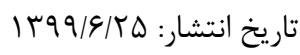

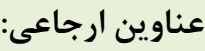
دياليز

\section{جكيده}

مقدمه: بيمارى كليوى موجب بروز مشكلات متعدد جسمانى و روانى براى فرد بيــــــار

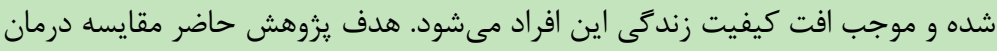

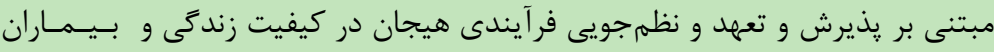

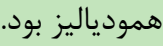

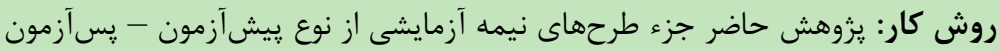

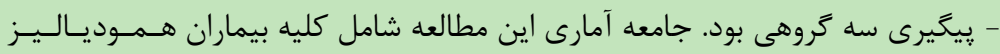

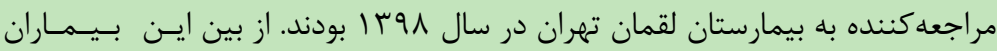

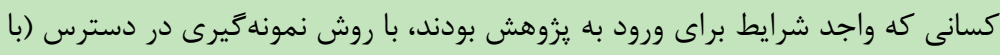

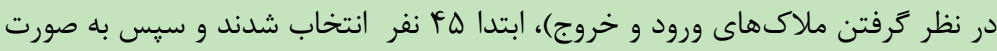

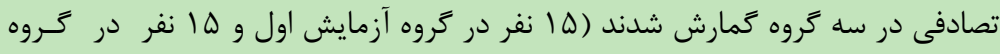

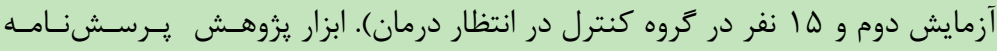

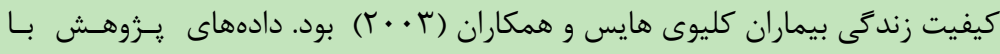

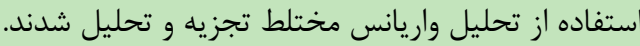

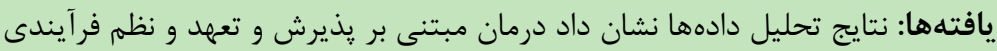

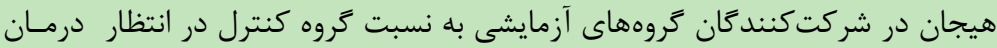

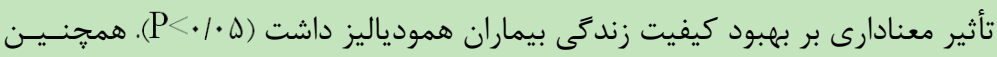

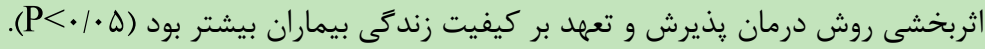

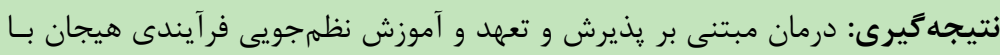

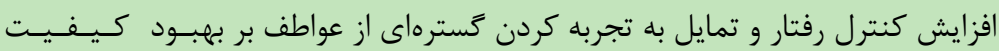

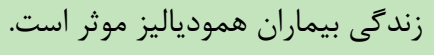

وازَّان كليدى: درمان مبتنى بر بذيرش و تعهد، نظهجويى فرآيندى هيجان، كيفيت

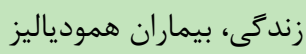

ا - دانشجوى دكتراى روانشناسى سلامت، كروه روانشناسى، واحد بين الملل كيش، دانشـــاه آزاد اسلامى، جزيره كيش، ايران

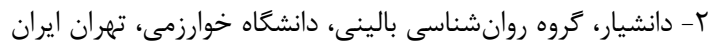

Hatami513@gmail.com (نويسنده مسئول)

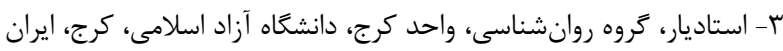

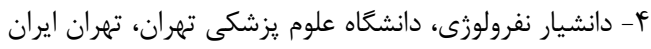

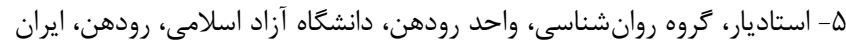


يذيرش و تعهد بر اضطراب و افسردگى (1))، كاهش تجربه درد

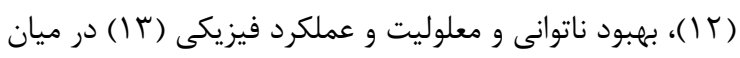
بيماران مزمن نشان دادهاند.

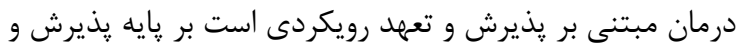

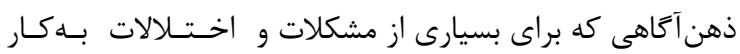

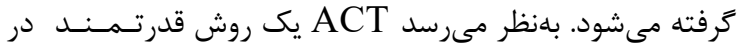

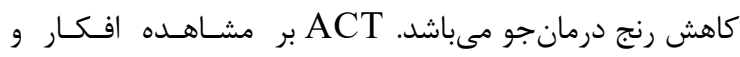

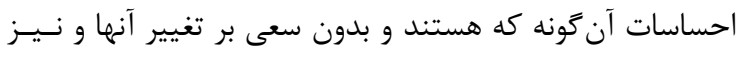

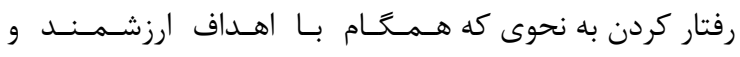

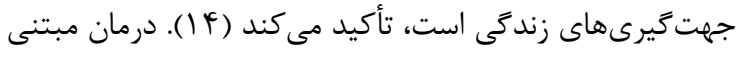

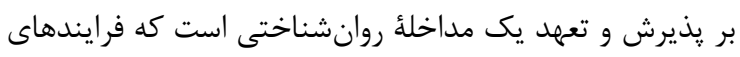

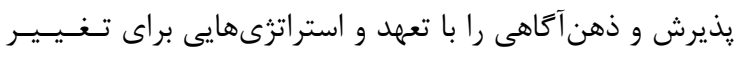

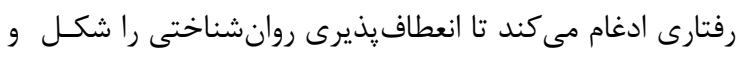

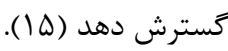

يكى ديكر از درمانهاى روانشناختى براى دمان كمك به افراد داراى

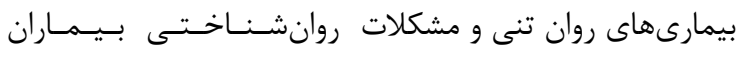

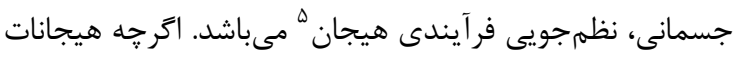

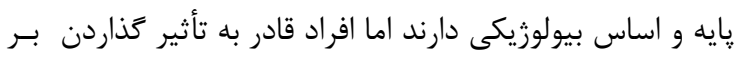

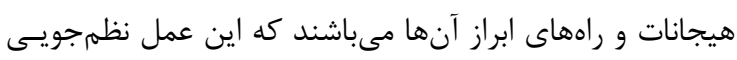

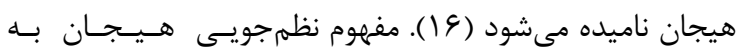

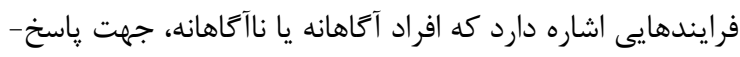
دهى مناسب به تقاضاهاى محيطى، به كار مىروند (IV)

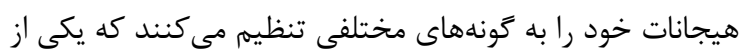

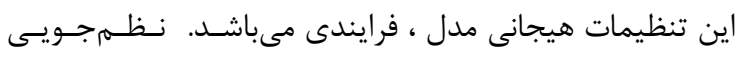

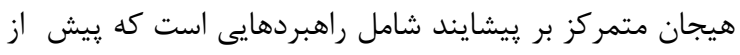

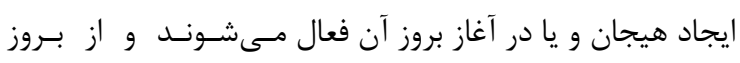

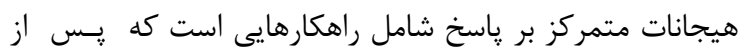

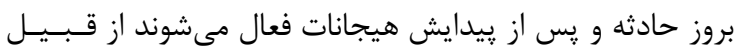

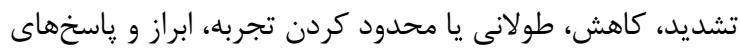
فيزيولوزيكى هيجانات و غيره (1) (1).

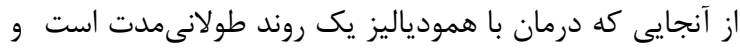

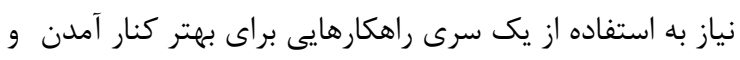

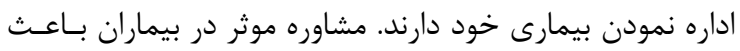

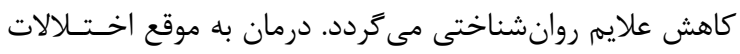

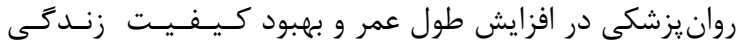

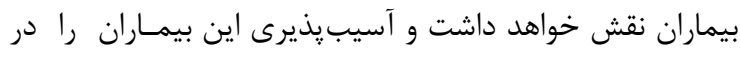

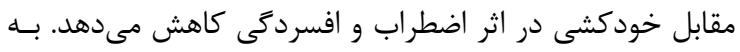

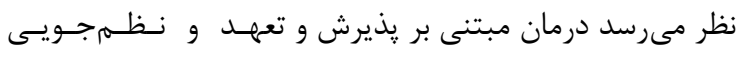

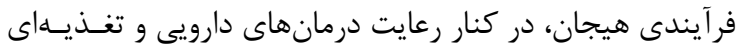

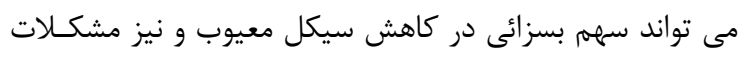

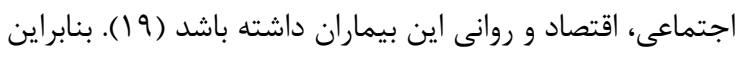

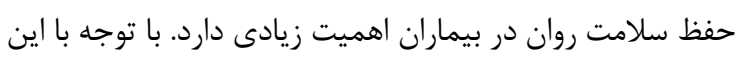

5- Process Emotion Regulation
مقدمه

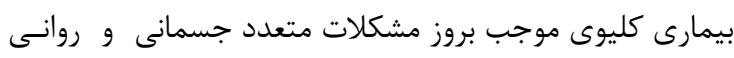

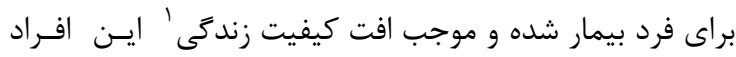
مى شود. درمانهاى مختلف مسئول ايجاد تغييرات قابل توجهى بئى

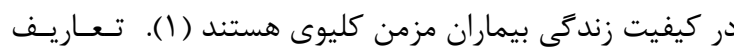

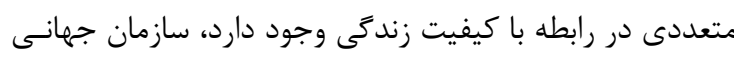

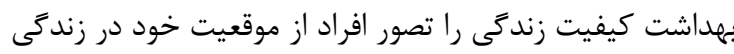

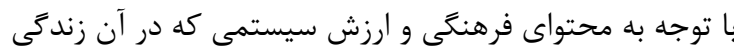

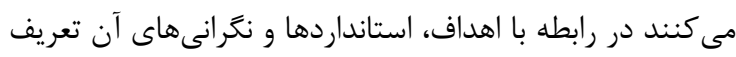

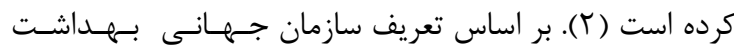

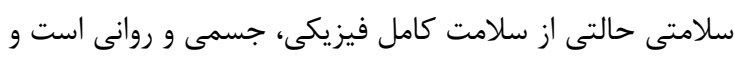

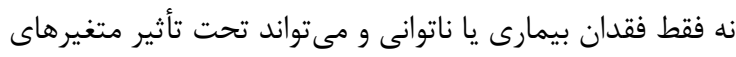

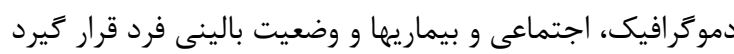

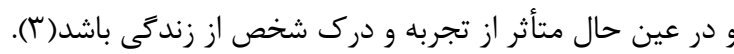

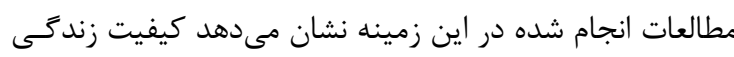

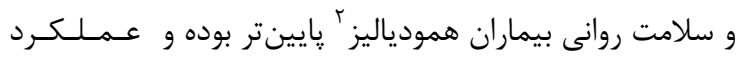

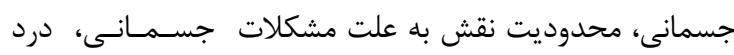

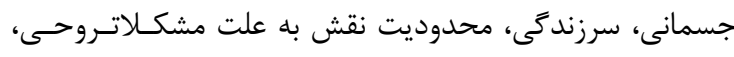

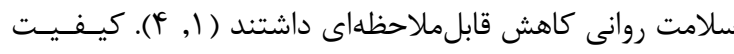

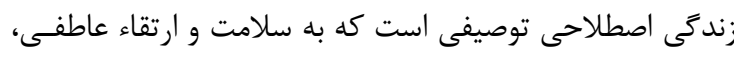

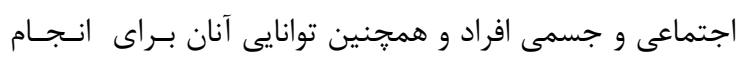
وظايف روزمره زندكى اشاره دارد (ه) (ه).

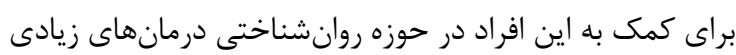

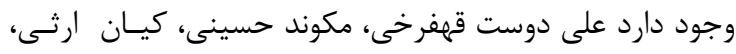

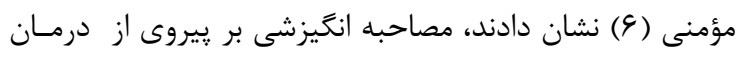

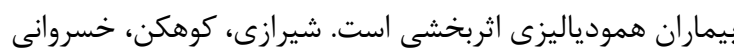

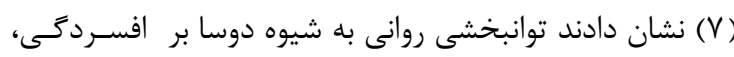

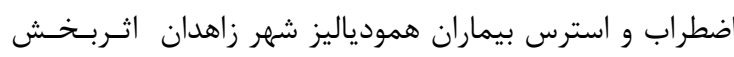

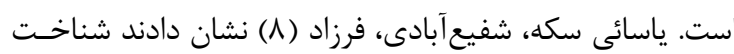

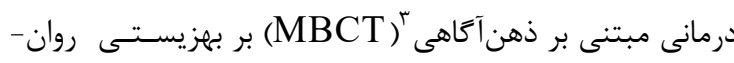

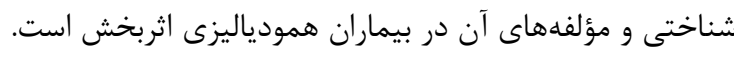

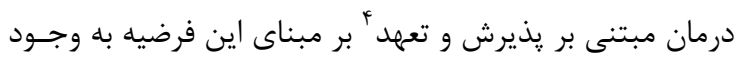

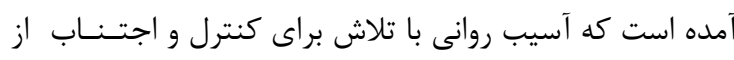

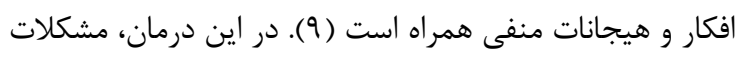

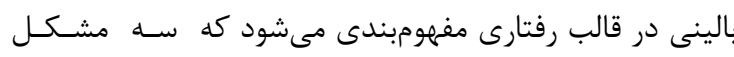

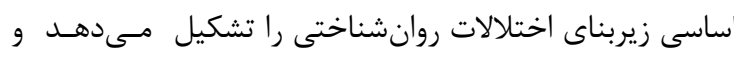

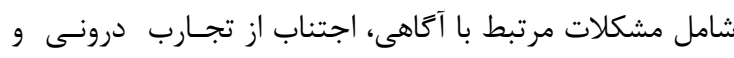

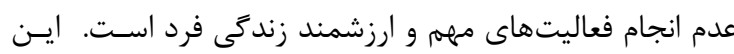

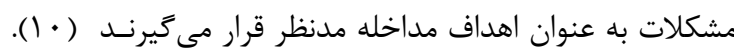

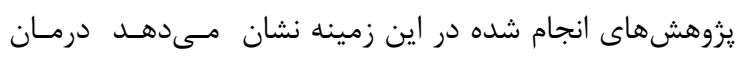

1- Quality of Life

2- Hemodialysis Patients

3- Mindfulness-Based Cognitive Therapy - MBCT

4- Acceptance and Commitment Therapy - ACT 
مطالعات كمى، از حيث هدف جزء مطالعات كاربردى و از نـظــر

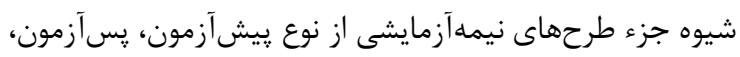

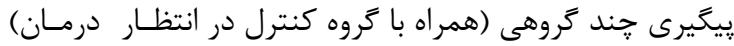

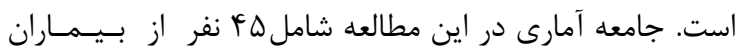

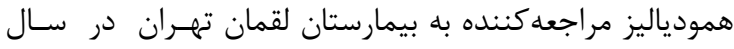

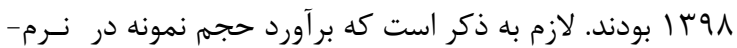

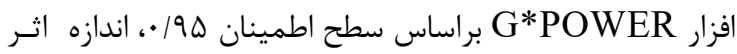

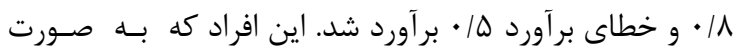

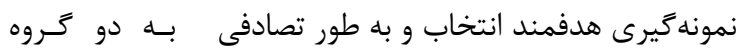

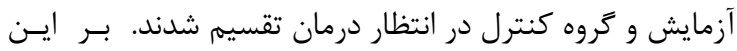

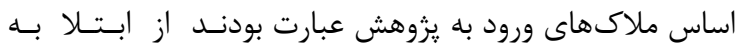

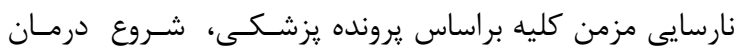

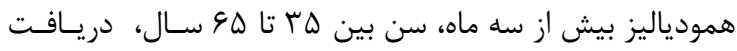

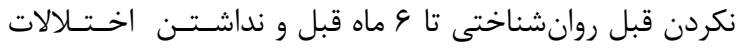
شخصيت و روان يريشى و سوءمصرف موادي.

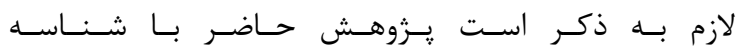

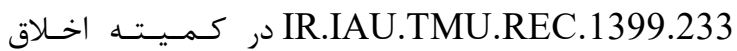
يزروهش دانشكاه آزاد اسلامى واحد علوم يزشكى ت تهــران بـهـ
كه بيمارىهاى مزمن از جمله نارسايى مزمن كليوى بر جنبـهـ-

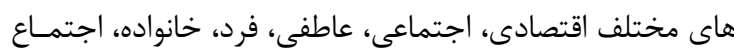

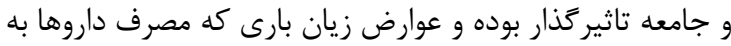

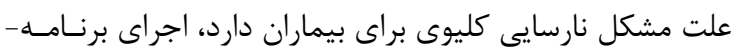

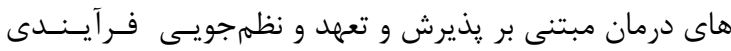

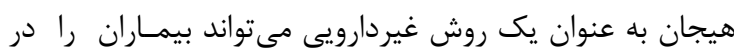

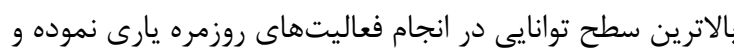

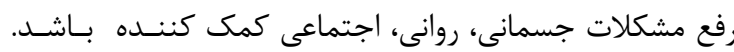

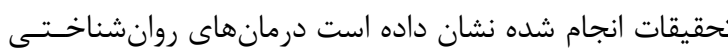

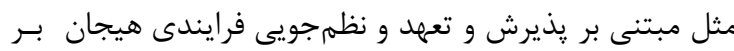

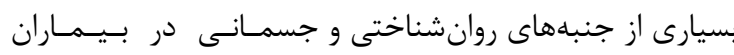

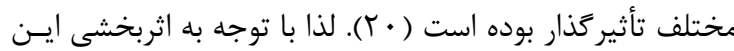

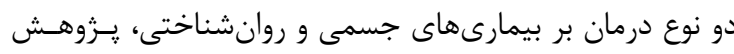

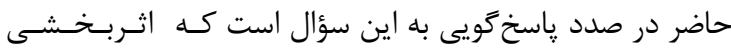

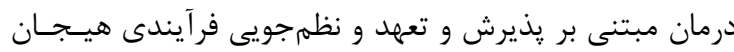

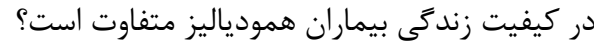

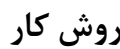
يزؤهش حاضر از نظر ماهيت دادهاى جمعآورى شـده جـزء

جدولا: خلاصه محتواى جلسات آموزش مبتنى بر بذيرش و تعهد، اقتباس از هيز، بيسترلو و لوين(I)

\begin{tabular}{|c|c|}
\hline 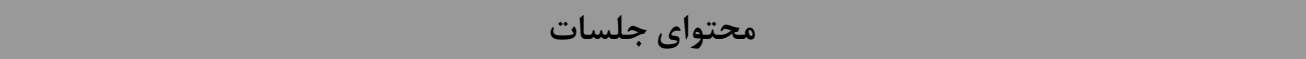 & جلسه \\
\hline آشنايى اعضاء با درمانكَر و يكديكر، آشنايى و توصيف كلى از رويكرد درمانى، قرارداد درمانى. & 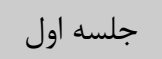 \\
\hline 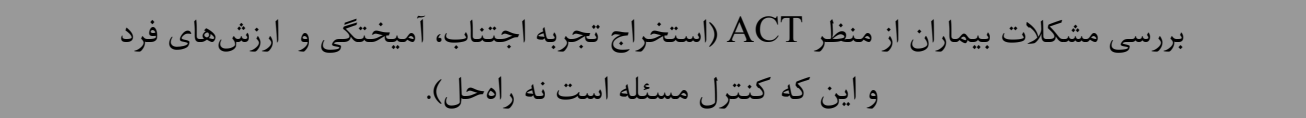 & 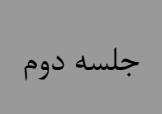 \\
\hline شفافسازى ناكارآمدى و كنترل رويدادهاى منفى با استفاده از استعارهها و آموزش تمايل & 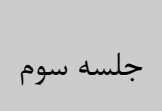 \\
\hline آموزش جدا كردن ارزيابى ها از تجارب شخصى، در نظر كرفتن خود به عنوان زمينه و اتخاذ موضع، مشاهده افكار & جلسه جهارم \\
\hline ارتباط با زمان حال و آموزش فنون ذهن آكاهى & جلسه ينجم \\
\hline شناسايى ارزشهاى زندگى بيماران و سنجش ارزشها بر مبناى ميزان اهميت آنها در زندكى & جلسه ششم \\
\hline 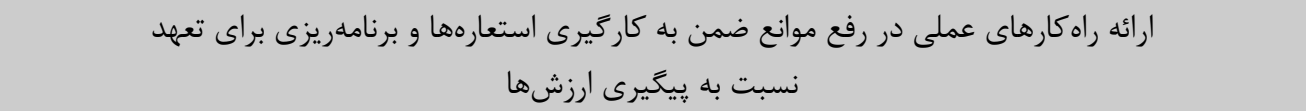 & جلسه هفتم \\
\hline 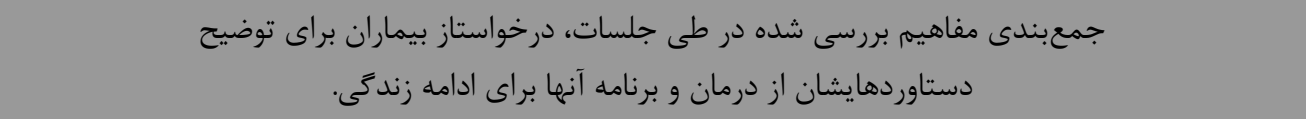 & جلسه هشتم \\
\hline
\end{tabular}


جلسات در جداول زير ارائه مىشود.

در اين يزوهش براى جمع آورى دادهيا از ابزارهاى ذئ ذيل استفاده

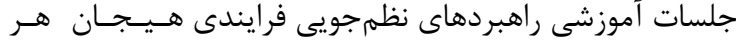

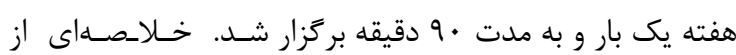

جدول r: خلاصه محتواى جلسات آموزشى راهبردهاى نظم جويى فرايندى هيجان مبتنى بر مدل كراوس (r (T)

\begin{tabular}{|c|c|c|}
\hline 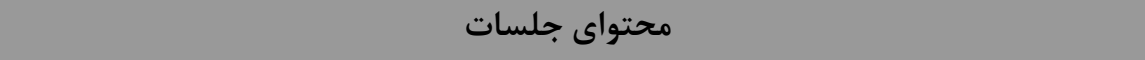 & 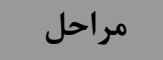 & 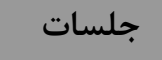 \\
\hline 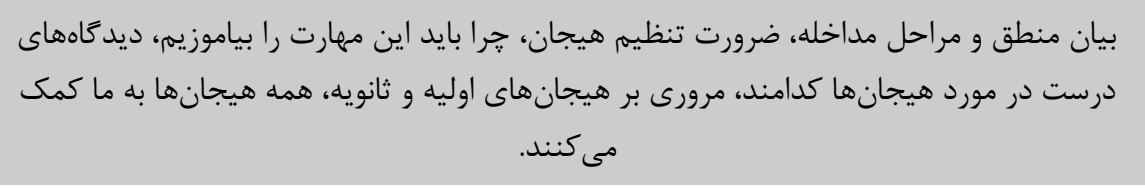 & & 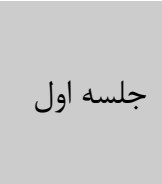 \\
\hline 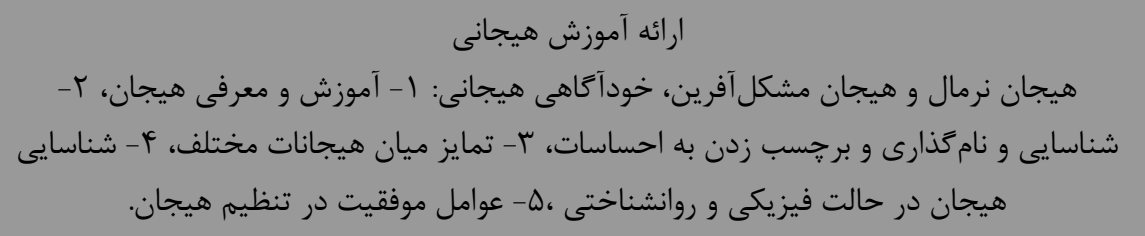 & 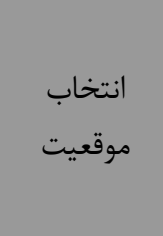 & 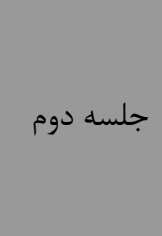 \\
\hline 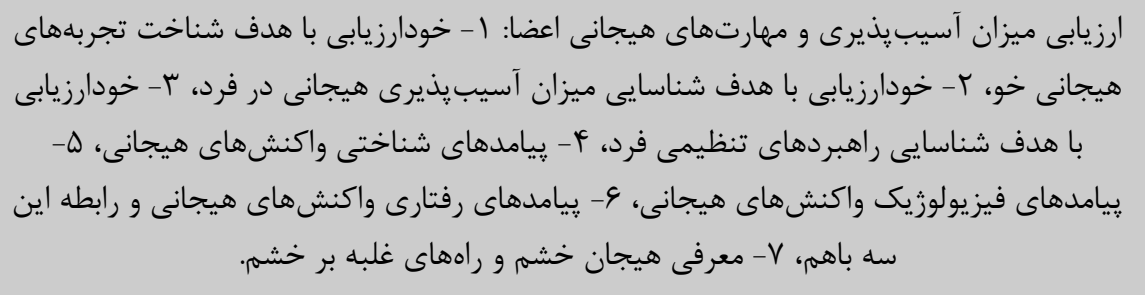 & 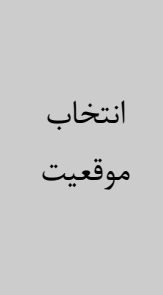 & 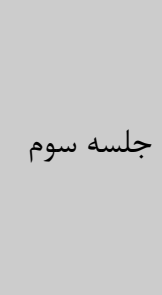 \\
\hline 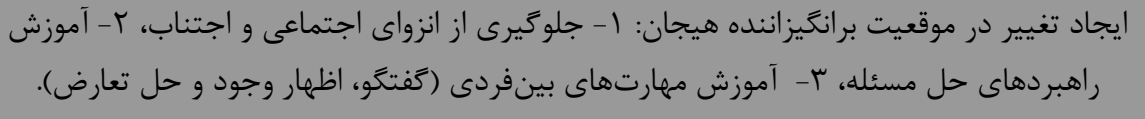 & 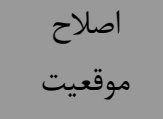 & 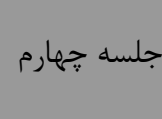 \\
\hline تغيير توجه: ا- متوقف كردن نشخوار فكرى و نكَرانى، ץ- آموزش توجه. & توجترش & جلسه ينجم \\
\hline تغيير ارزيابىهاى شناختى: ا- شناسايى ارزيابىهاى غلط و اثرات آنها روى حالتهاى هيجانى و & 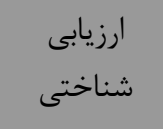 & جلسه ششم \\
\hline 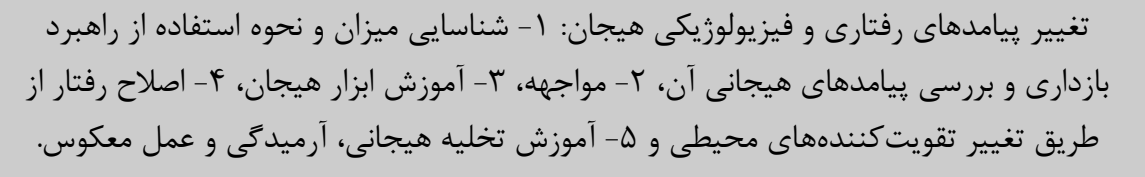 & تعديل ياسخ & جلسه هفتم \\
\hline 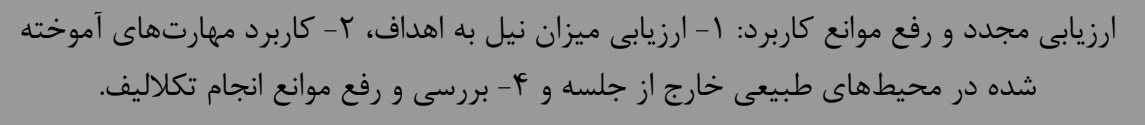 & كاركرد & جلسه هشتم \\
\hline مرور جلسات و تمرين مهارتهاى آموخته شده. & & جلسه نهم \\
\hline
\end{tabular}

اختصاصى KDQOL-SF

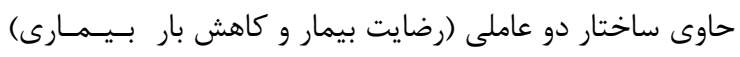

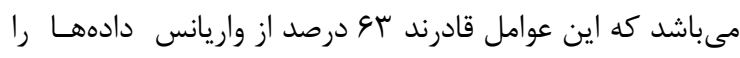

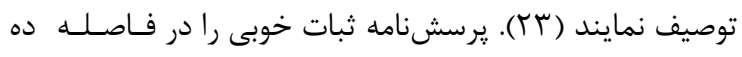

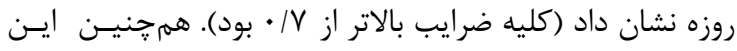

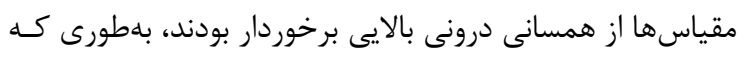

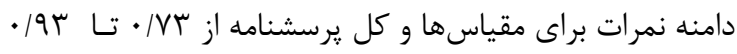

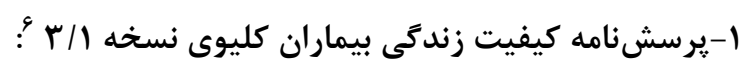

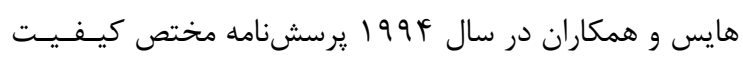

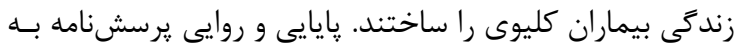

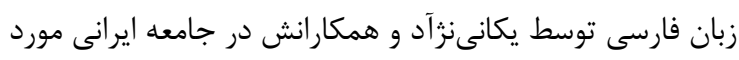

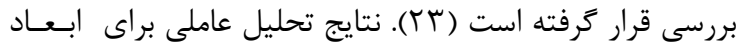

6- Kidney disease quality of life - KDQOL 
״رسشنامه شامل جنسيت، سن، تحصيلات، و سـابـــه درمـان

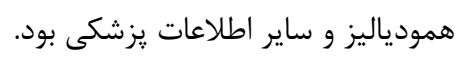

\section{يافتهها}

تحليل دادههاى جمعيت شناختى نشان داد در هر كروه V نـفــــ

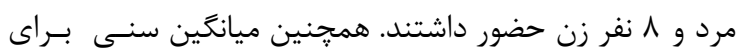

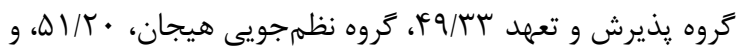

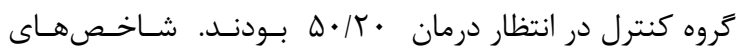

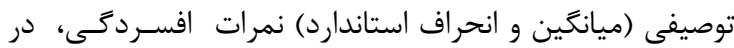

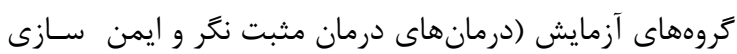

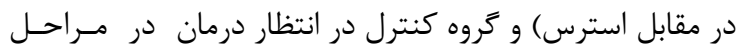

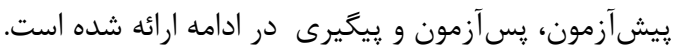

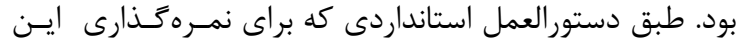

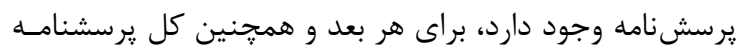

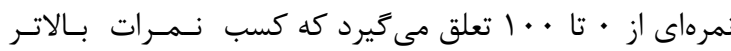

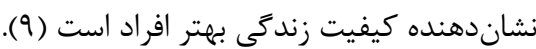

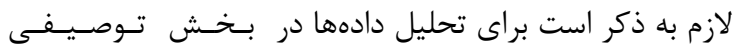

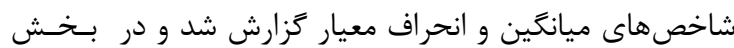

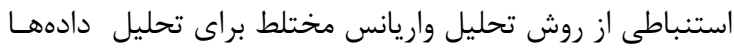
ستفاده شد.

\section{r- برسشنامه اطلاعات جمعيتشناختى محققساخته: به}

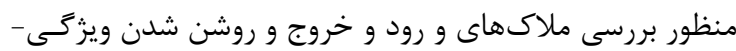

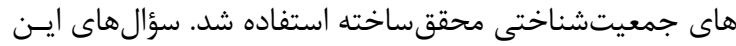

\section{جدول بّ: ميانكَين و انحراف معيار كيفيت زندكى به تفكيك مرحله سنجش در كروهها}

\begin{tabular}{|c|c|c|c|c|c|}
\hline هيخيرى & هِ آزمون & بيش آزمون & شاخص & متغير & كروه \\
\hline$\Delta \Delta / \mathcal{F V}$ & $\Delta F / F V$ & FN/DT & ميانََين & \multirow{2}{*}{ زنديفيت } & \multirow{2}{*}{ يذيرش و تعهد } \\
\hline$r / T V$ & $r / T V$ & $\mathcal{F} / \wedge \Delta$ & انحراف معيار & & \\
\hline$\Delta T / \cdot$ & $\Delta r / F V$ & $<9 / 9 V$ & ميانكَين & \multirow{2}{*}{ زنديفيت } & \multirow{2}{*}{ نظم } \\
\hline T/IF & צr/T & $r / 9 F$ & انحر اف معيار & & \\
\hline FV/qr & FN/T. & FN/AV & ميانكين & \multirow{2}{*}{ زنديفيت } & \multirow{2}{*}{ كنترل } \\
\hline$r / \cdot T$ & T/V^ & $r / \cdot r$ & انحراف معيار & & \\
\hline
\end{tabular}

نسبت به بيش آزمون افزايش نشان ميدهد.

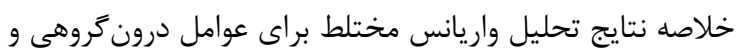
بينَّرهى در جدول بأ ارائه شده است
همجنان كه ملاحظه مى شود ميانكَين در كروه درمان مبتنى بـر

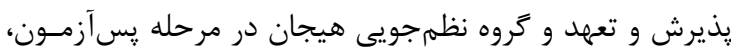

جدول \&: آزمون تحليل واريانس مختلط نمرات كيفيت زندكى با معيار ترين هاوس تيزر

\begin{tabular}{|c|c|c|c|c|c|c|}
\hline ضريب ايتا & Sig & $\mathbf{F}$ & MS & df & SS & شاخص آمارى \\
\hline .119 & $\cdot / \cdot r$ & $9 / 99$ & $V \cdot \Delta / \varphi$. & $1 / \cdot$ & $V \cdot \Delta / \varphi$. & آزمون(تكرار اندازه) \\
\hline | l &.$/ . .1$ & $\mid r / 9 V$ & $V I / f \Delta$ & $1 / 19$ & AT/AT & تعامل آزمون* كروه \\
\hline.$/ 1 T$ & $\cdot / \cdot t$ & $F / \wedge \Delta$ & $49 / 94$ & $1 / \cdot$ & re/qf & بين كروهى \\
\hline
\end{tabular}

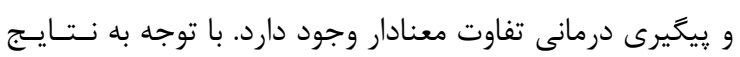

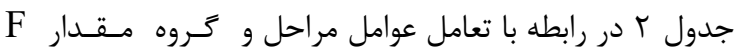

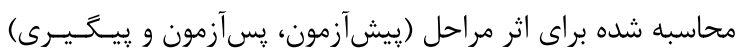

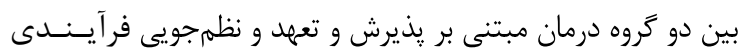

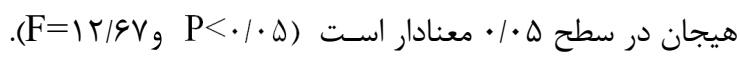

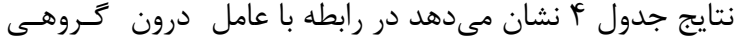

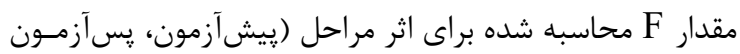

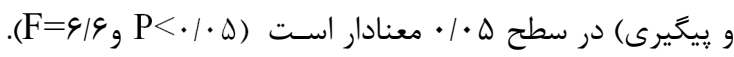

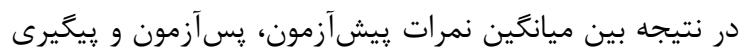

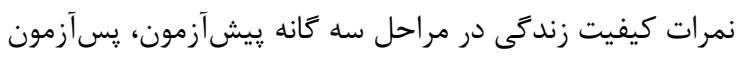




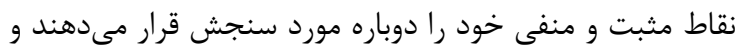

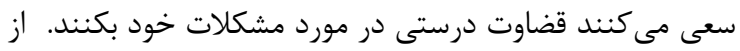

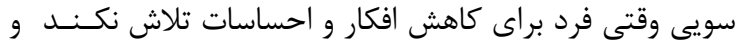

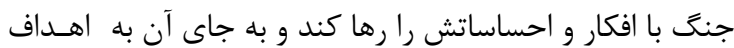
تعيين شده در جهتهاى ارزشمند زندكى حركت كند، افزايسش

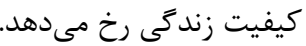

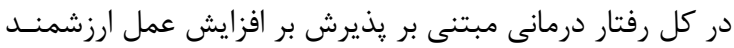

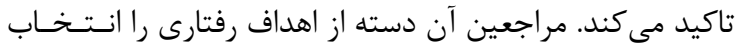

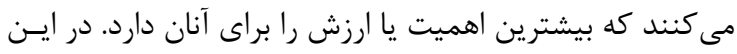

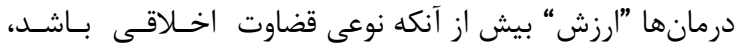

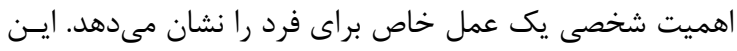

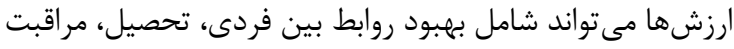

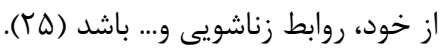

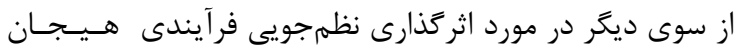

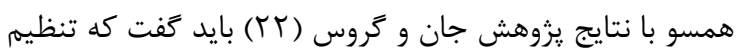

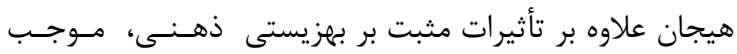

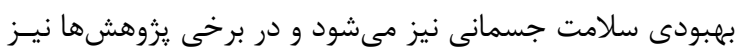

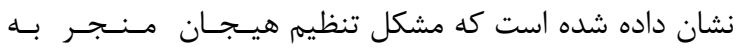

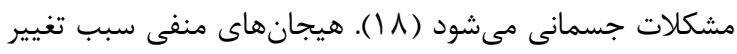

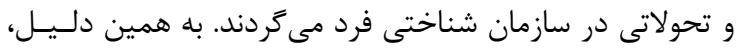

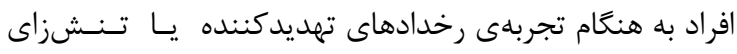

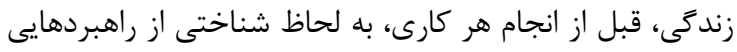

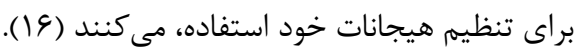

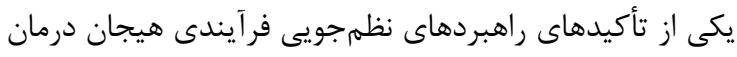

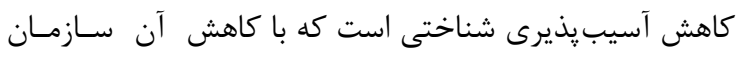

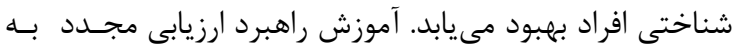

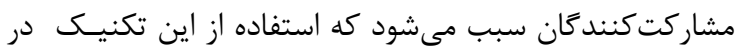

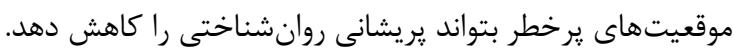

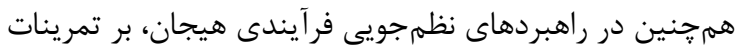

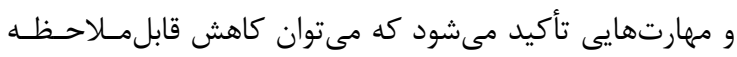

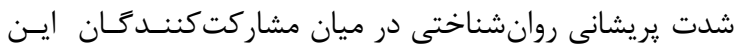

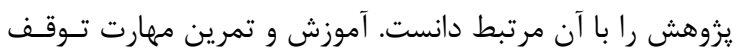

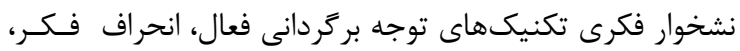

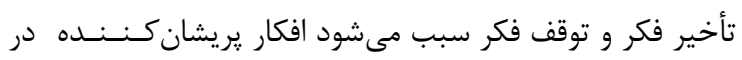

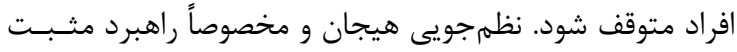

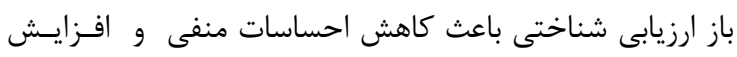

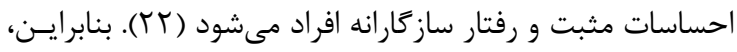

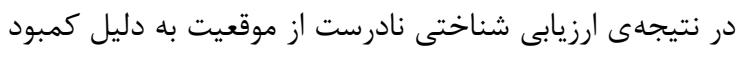

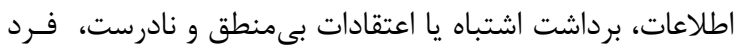

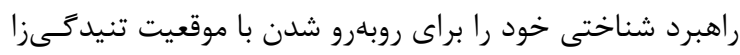

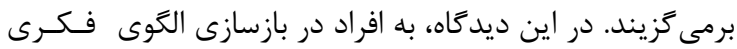

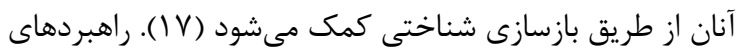

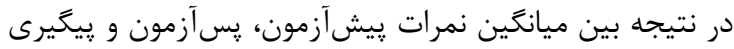
كيفيت زندگى در دو كروه تفاوت معنادار وجود دارد.

\section{بحث و نتيجه}

نتايج تحليل دادهها نشان داد كه تفاوت معنادارى بين اثربخشى نقي

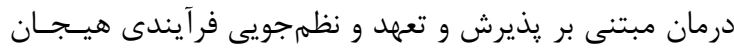

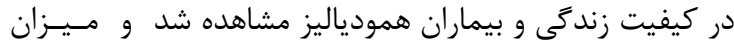

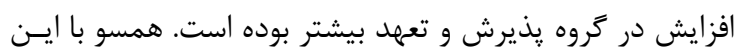

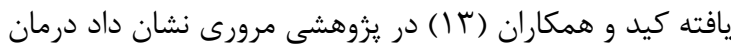

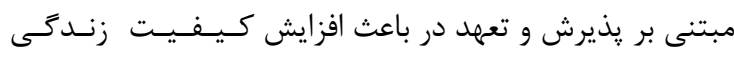

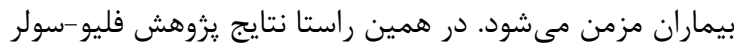

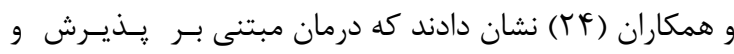

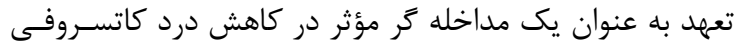

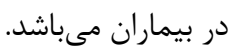

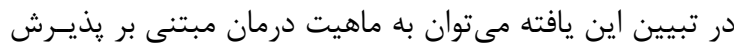

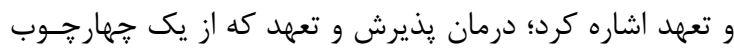

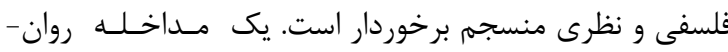

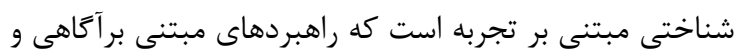

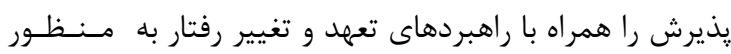

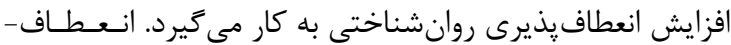

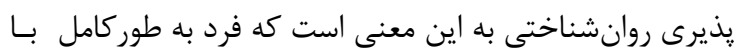

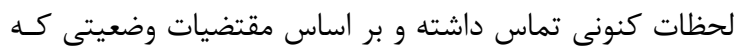

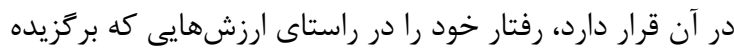

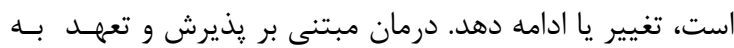

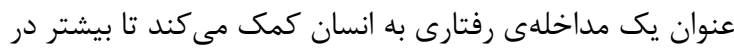

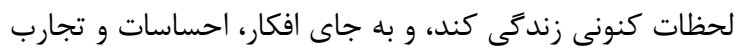

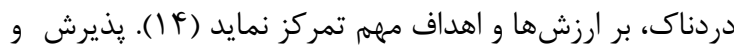

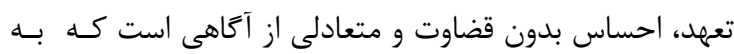

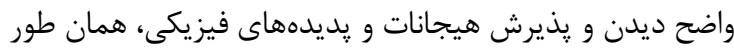

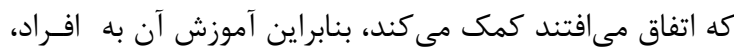

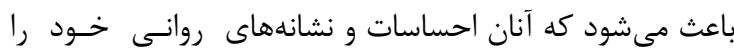
بيذيرند و قبول و يذيرش اين احساسات و افكار، باعث كـاهـش

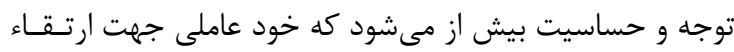

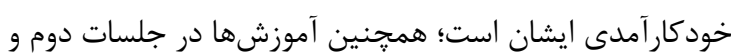

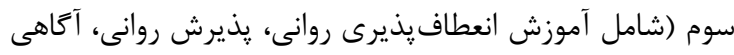

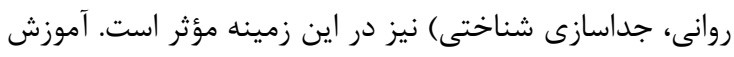

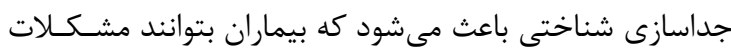

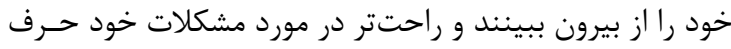

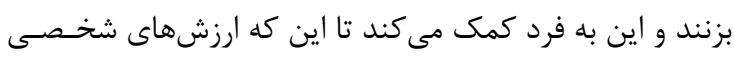

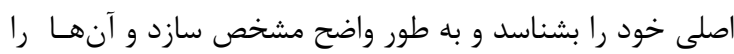

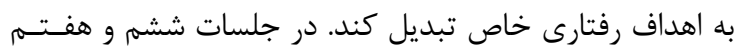

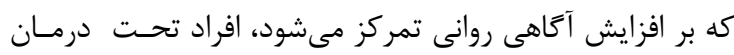


اجرايى از مصاحبه براى كردآورى دادههاى يزوهش اســـــــــاده

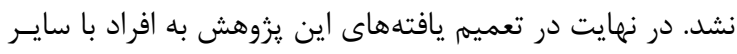

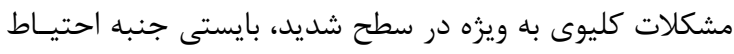

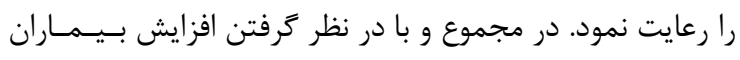

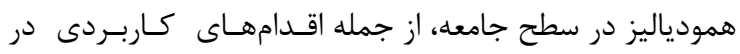

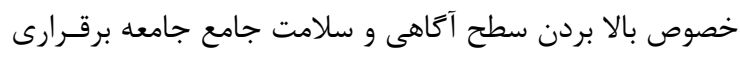

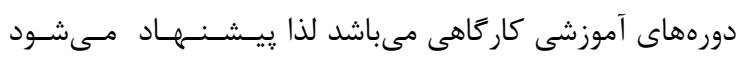

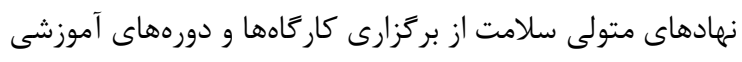

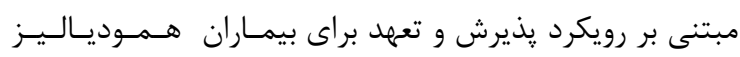

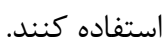

\section{تشكر و قدردانى}

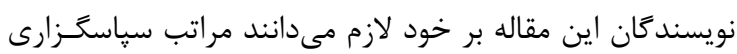

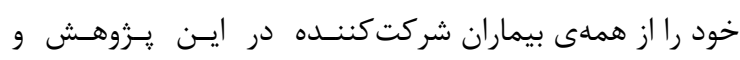

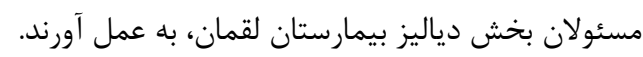

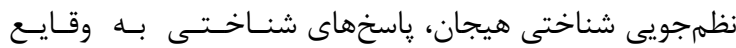

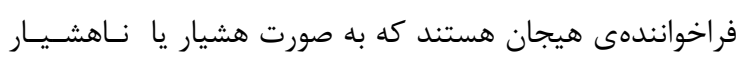

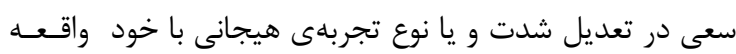

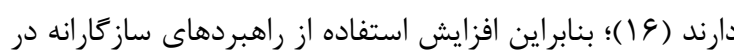

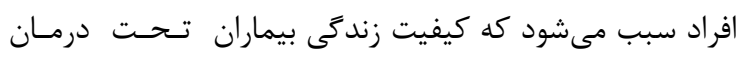

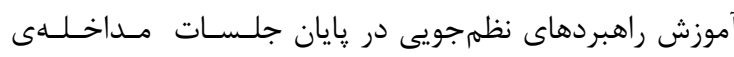

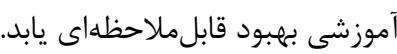

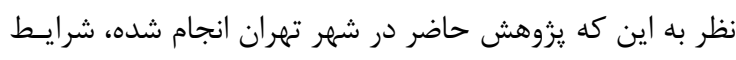

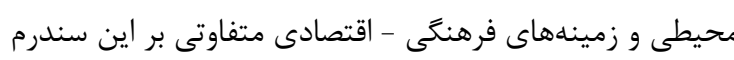

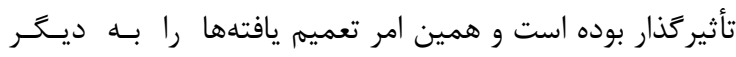

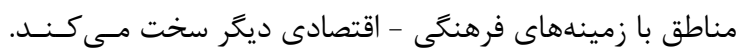

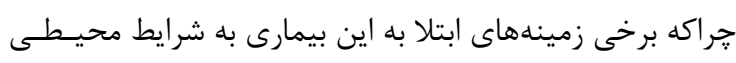

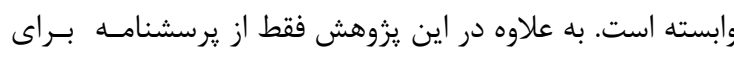

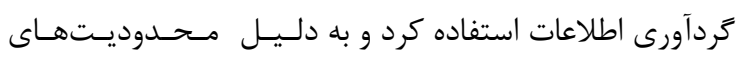




\section{References}

1- Ferreira RC, Silva Filho CRd. Quality of life of chronic renal patients on hemodialysis in Marília, SP, Brazil. Brazilian Journal of Nephrology. 2011;33(2):129-35.

2- Najafi M, SHEYKH VM, Montazeri A, ABBASI SHA, SHEYKH FEM. Quality of life in coronary artery disease: SF-36 compared to WHOQOL-BREF. 2008.

3- Cervino G, Terranova A, Briguglio F, De Stefano $\mathrm{R}$, Famà $\mathrm{F}$, D'Amico $\mathrm{C}$, et al. Diabetes: Oral health related quality of life and oral alterations. BioMed research international. 2019;2019.

4- de Abreu MM, Walker DR, Sesso RC, Ferraz MB. Health-related quality of life of patients recieving hemodialysis and peritoneal dialysis in São Paulo, Brazil: a longitudinal study. Value in health. 2011;14(5):S119-S21.

5- Valles-Colomer M, Falony G, Darzi Y, Tigchelaar EF, Wang J, Tito RY, et al. The neuroactive potential of the human gut microbiota in quality of life and depression. Nature microbiology. 2019;4(4):623-32.

6- Alidoust Ghahfarokhi f, Makvand Hosseini S, Kiyan Ersi F, Moemeni A. Effectiveness of motivational interviewing on treatment adherence in dialysis patients in Hajar hospital of Shahrekord, 2013. Journal of Shahrekord Uuniversity of Medical Sciences. 2015;17(4):17-24.

7- Shirazi M, Koohkan azim H, Khosravani E. Effectiveness of psychological rehabilitation, using Dohsa-Hou, on hemodialysis patients' depression, anxiety, and stress in Zahdan city. Journal of Birjand University of Medical Sciences. 2016;23 (2):130-40.

8- yasaei sekeh m, Shafiabadi A, Farzad V. Effectiveness of Mindfulness-Based Cognitive Therapy (MBCT) on psychological well-bing and Its Components in hemodialysis patients. Scientific Journal Management System. 2018;13(55):149-62.

9- Hays RD, Kallich JD, Mapes DL, Coons SJ, Carter WB. Development of the kidney disease quality of life (KDQOL TM) instrument. Quality of life Research. 1994;3(5):329-38.

10- Karekla M, Panayiotou G. Coping and experiential avoidance: Unique or overlapping constructs? Journal of behavior therapy and experimental psychiatry. 2011;42(2):163-70.

11- Pingo JC, Dixon MR, Paliliunas D. Intervention Enhancing Effects of Acceptance and Commitment Training on Performance Feedback for Direct Support Professional Work Performance, Stress, and Job Satisfaction. Behavior Analysis in Practice. 2019:1-10.

12- Roditi D, Robinson ME. The role of psychological interventions in the management of patients with chronic pain. Psychology research and behavior management. 2011;4:41.

13- Kidd T, Mold F, Jones C, Ream E, Grosvenor $\mathrm{W}$, Sund-Levander M, et al. What are the most effective interventions to improve physical performance in pre-frail and frail adults? A systematic review of randomised control trials. BMC geriatrics. 2019;19(1):184.
14- Hayes SC, Luoma JB, Bond FW, Masuda A, Lillis J. Acceptance and commitment therapy: Model, processes and outcomes. Behaviour research and therapy. 2006;44(1):1-25.

15- Harris R. ACT made simple: An easy-to-read primer on acceptance and commitment therapy: New Harbinger Publications; 2019.

16- Garnefski N, Teerds J, Kraaij V, Legerstee J, van Den Kommer T. Cognitive emotion regulation strategies and depressive symptoms: Differences between males and females. Personality and individual differences. 2004;36(2):267-76.

17- Rood L, Roelofs J, Bögels SM, NolenHoeksema S, Schouten E. The influence of emotion -focused rumination and distraction on depressive symptoms in non-clinical youth: A meta-analytic review. Clinical psychology review. 2009;29 (7):607-16.

18- JJ G. Thompson RA. Emotion regulation: conceptual foundations. Gross JJ. Handbook of emotion regulation. New York: Guilford press; 2007.

19- Jonsjö MA, Wicksell RK, Holmström L, Andreasson A, Olsson GL. Acceptance \& commitment therapy for ME/CFS (chronic fatigue syndrome)-a feasibility study. Journal of Contextual Behavioral Science. 2019;12:89-97.

20- Freud D, Levy-Kardash O, Glick I, EzratiVinacour R. Pilot program combining acceptance and commitment therapy with stuttering modification therapy for adults who stutter: A case report. Folia Phoniatrica et Logopaedica. 2020;72(4):290301.

21-Hayes SC, Pistorello J, Levin ME. Acceptance and commitment therapy as a unified model of behavior change. The Counseling Psychologist. 2012;40(7):976-1002.

22-Gross JJ, John OP. Individual differences in two emotion regulation processes: implications for affect, relationships, and well-being. Journal of personality and social psychology. 2003;85(2):348. 23-Yekaninejad M, Mohammadi Zeidi I, Akaberi A, Golshan A, Pakpour Haji Agha, A. Validity and reliability of the Kidney Disease Quality of Life Short Form (KDQOL-SFTM 1.3) in Iranian patients. JNKUMS, 2012; 4(2): 261-272. (Persian)

24-Feliu-Soler A, Montesinos F, GutiérrezMartínez O, Scott W, McCracken LM, Luciano JV. Current status of acceptance and commitment therapy for chronic pain: a narrative review. Journal of pain research. 2018;11:2145.

25-Vowles KE, Sowden G, Hickman J, Ashworth J. An analysis of within-treatment change trajectories in valued activity in relation to treatment outcomes following interdisciplinary Acceptance and Commitment Therapy for adults with chronic pain. Behaviour research and therapy. 2019;115:46-54. 